\title{
99mTc-3PRGD2 for Integrin Receptor Imaging of Lung Cancer: A Multicenter Study
}

\author{
Zhaohui Zhu ${ }^{1}$, Weibing Miao ${ }^{2}$, Qianwei $\mathrm{Li}^{3}$, Haojie Dai ${ }^{4}$, Qingjie $\mathrm{Ma}^{5}$, Feng Wang ${ }^{6}$, Aiming Yang ${ }^{7}$, Bing $\mathrm{Jia}^{8}$, \\ Xiaona Jing ${ }^{1}$, Sha Liu ${ }^{1}$, Jiyun $\mathrm{Shi}^{8}$, Zhaofei $\mathrm{Liu}^{8}$, Zhoushe Zhao ${ }^{9}$, Fan Wang ${ }^{8}$, and $\mathrm{Fang} \mathrm{Li}^{1}$ \\ ${ }^{1}$ Department of Nuclear Medicine, Peking Union Medical College Hospital, Chinese Academy of Medical Sciences and Peking Union \\ Medical College, Beijing, China; ${ }^{2}$ Department of Nuclear Medicine, the 1st Affiliated Hospital of Fujian Medical University, Fuzhou, \\ China; ${ }^{3}$ Department of Nuclear Medicine, Southwest Hospital of the Third Military Medical University, Chongqing, China; \\ ${ }^{4}$ Department of Nuclear Medicine, Beijing Tongren Hospital, Beijing, China; ${ }^{5}$ Department of Nuclear Medicine, China-Japan Union \\ Hospital of Jilin University, Changchun, China; ${ }^{6}$ Department of Nuclear Medicine, the 1st Hospital of Nanjing, Nanjing, China; \\ ${ }^{7}$ Department of Nuclear Medicine, the 1st Affiliated Hospital of Xi'an Jiaotong University, Xi'an, China; ${ }^{8}$ Medical Isotopes Research \\ Center, Peking University, Beijing, China; and ${ }^{9}$ GE Healthcare, Beijing, China
}

\begin{abstract}
99mTc-3PRGD2 is a new SPECT tracer targeting integrin $\alpha_{\mathrm{V}} \beta_{3}$ receptor for detecting tumors, imaging angiogenesis, and evaluating tumor response to therapy. A multicenter study was designed to investigate the efficacy of 99mTc-3PRGD2 for the evaluation of patients with lung cancer. Methods: Seventy patients (51 men, 19 women; mean age $\pm S D, 63 \pm 9$ y) with a suspected lung lesion and for whom definite pathologic diagnosis was finally obtained (malignant, $n=58$; benign, $n=12$ ) were recruited from 6 centers. Whole-body planar scanning and chest SPECT were performed at 1 and $4 \mathrm{~h}$, respectively, after intravenous injection of $11.1 \mathrm{MBq} / \mathrm{kg}(0.3 \mathrm{mCi} / \mathrm{kg})$ of ${ }^{99 \mathrm{mTc}-}$ 3PRGD2. The images were read in consensus by 6 experienced nuclear medicine physicians masked to the source, history, and pathologic diagnosis. The tumor-to-background (T/B) ratios were calculated for semiquantitative analysis. A Student $t$ test was used for statistical analysis, and a $P$ value less than 0.05 was considered significant. Results: With low 99mTc-3PRGD2 background in the lungs and mediastinum, most lung malignancies were prominent on the $1-\mathrm{h}$ images (T/B ratio, $1.65 \pm 0.47$ for the planar imaging and $2.78 \pm 1.52$ for SPECT). The T/B ratios were significantly lower in the benign lesions $(P<0.05)$. The sensitivity was $88 \%$ for semiquantitative analysis and could reach $93 \%-97 \%$ in visual analysis when considering the volume effect, necrosis, and metastasis. However, the specificity was only $58 \%-67 \%$. Most lymph node and bone metastases could also be detected. Conclusion: ${ }^{99 m T c-3 P R G D 2 ~ i m a g i n g ~ a t ~} 1 \mathrm{~h}$ is sensitive for the detection of lung cancer, meriting further investigation of $99 \mathrm{mTc}-3 \mathrm{PRGD} 2$ as a novel clinical tracer for integrin receptor imaging.
\end{abstract}

\footnotetext{
Received Oct. 5, 2011; revision accepted Jan. 3, 2012.

For correspondence or reprints contact either of the following:

Fang Li, Department of Nuclear Medicine, Peking Union Medical College Hospital, No. 1 Shuaifuyuan, Wangfujing St., Dongcheng District, Beijing 100730, China.

E-mail: lifang@pumch.cn

Fan Wang, Medical Isotopes Research Center, Peking University, Beijing 100191, China.

E-mail: wangfan@bjmu.edu.cn

Published online Apr. 12, 2012.

COPYRIGHT @ 2012 by the Society of Nuclear Medicine, Inc.
}

Key Words: 99mTc-3PRGD2; integrin $\alpha_{v} \beta_{3}$; lung cancer; multicenter study; SPECT

J Nucl Med 2012; 53:716-722

DOI: 10.2967/jnumed.111.098988

\section{O}

ince integrins were revealed as an important family of transmembrane receptors about $30 \mathrm{y}$ ago, they have been widely studied and are found to play essential roles in angiogenesis and tumor metastasis because they are mainly involved in the cell-cell and cell-matrix interactions (1). Integrin $\alpha_{V} \beta_{3}$ is an important member of this receptor family and expressed preferentially on various types of tumor cells and the activated endothelial cells of tumor angiogenesis but not at all or very little on the quiescent vessel cells and other normal cells $(2,3)$. Therefore, the integrin $\alpha_{V} \beta_{3}$ receptor is becoming a valuable target for diagnosis and treatment of malignant tumors $(4,5)$.

The tripeptide sequence of arginine-glycine-aspartic acid (RGD) can specifically bind to the integrin $\alpha_{V} \beta_{3}$ receptor $(6,7)$. Accordingly, a variety of radiolabeled RGD-based peptides have been developed for noninvasive imaging of integrin $\alpha_{v} \beta_{3}$ expression via PET or SPECT (8-17). Among all the RGD radiotracers studied, 2 PET agents, ${ }^{18} \mathrm{~F}$-galactoRGD and ${ }^{18} \mathrm{~F}-\mathrm{AH} 111585$, have been well investigated in clinical trials. The results demonstrated that both radiotracers allowed the specific imaging of various types of tumors, and the tumor uptake correlated well with the expression of integrin $\alpha_{\mathrm{v}} \beta_{3}$ in both animal models and patients (9-14). The ${ }^{99 \mathrm{~m}} \mathrm{Tc}$-labeled RGD peptides for SPECT are rarely studied, and fewer peptides have been translated into clinical use. ${ }^{99 \mathrm{~m}} \mathrm{Tc}-\mathrm{NC} 100692$, a ${ }^{99 \mathrm{~m}} \mathrm{Tc}-$ labeled cyclic peptide that contains a monomer RGD tripeptide sequence, has been proved potentially feasible for detection of breast and lung cancers in human beings $(16,17)$. Recently, series of ${ }^{99 m}$ Tc-labeled RGD dimeric 
peptides with $\mathrm{PEG}_{4}$ and $\mathrm{Gly}_{3}$ linkers have been studied (18-20). The new types of RGD peptides showed much higher in vitro integrin $\alpha_{v} \beta_{3}$ binding affinity than the single RGD tripeptide sequence, and they exhibited significantly increased tumor uptake and improved in vivo kinetics in animal models. As a representative, ${ }^{99 \mathrm{~m}} \mathrm{Tc}-3 \mathrm{PRGD} 2$ could be easily prepared in a kit formulation and exhibited excellent in vivo behaviors in nonhuman primates (21). Recently, it was used in patients and appeared useful for differentiation of solitary pulmonary nodules (22). ${ }^{99 \mathrm{~m} T c-3 P R G D 2}$ is mainly excreted by the kidneys. It has a rapid blood clearance, with less than $1 \%$ of the initial radioactivity remaining in the blood circulation at $60 \mathrm{~min}$ after injection (21). No adverse reactions are observed in animal models and humans to date (18-22).

For the further interests in clinical translation of ${ }^{99 \mathrm{~m} T c-}$ 3PRGD2, a multicenter study was designed to evaluate the efficacy of ${ }^{99 m}$ Tc-3PRGD2 for identification of lung cancer in a relatively large sample size. The values of ${ }^{99 \mathrm{~m} T \mathrm{~T}-3 \mathrm{PRGD} 2}$ for differentiation diagnosis and metastasis assessment were also preliminarily investigated. Moreover, to establish an easy and effective method for clinical use, different imaging protocols and analysis methods were compared.

\section{MATERIALS AND METHODS}

\section{Patient Recruitment}

This multicenter clinical trial was approved by the ethics committee of Chinese Academy of Medical Sciences and Peking Union Medical College Hospital and the institute review board of each participating center. From February 24 to June 30, 2011, 70 patients with suspected lung lesions and for whom definite pathologic diagnosis was finally obtained were recruited from 6 Chinese centers (Table 1) and then entered for the centralized analysis procedure. Written informed consent was obtained from each patient. The main inclusion criterion was that the patients had lung lesions in suspected primary cancer according to the findings of a CT scan obtained within $2 \mathrm{wk}$. The standard of truth for diagnosis was based on histopathologic findings after surgical removal of the tumor or a definite diagnosis from needle or bronchoscopy biopsy. For those patients diagnosed as benign by biopsy, the recommendation was to follow up until remission of the lesion was definitely observed without chemo- or radiotherapy. The exclusion criteria included pregnancy, lactation, and impaired renal or liver function. Those patients contrary to the standard operating procedures or without a definite pathologic diagnosis before the early analysis of this study were also excluded.

The 70 patients included 19 women and 51 men, aged 41-85 y (mean age $\pm \mathrm{SD}, 63 \pm 9 \mathrm{y}$ ). The size of lung lesions ranged from 1.0 to $10.4 \mathrm{~cm}$ (mean $\pm \mathrm{SD}, 4.3 \pm 2.0 \mathrm{~cm}$ ). Fifty-eight patients were proven to have malignancy, mainly adenocarcinoma $(n=$ 23 ) or squamous cell carcinoma $(n=24)$ of the lung; 12 patients were diagnosed with benign lesions, and 7 were thought to have chronic inflammation. The basic information for the patients is listed in Table 2.

In the 58 patients with malignant lung lesions, 55 had suspected metastases according to the comprehensive imaging work-up, mainly CT and ultrasonography. Twenty-one patients also underwent bone scanning, and 16 patients underwent ${ }^{18} \mathrm{~F}-\mathrm{FDG}$ PET/CT for comparison. All the other imaging studies were performed within 2 wk before or after ${ }^{99 m}$ Tc-3PRGD2 scanning.

\section{Radiopharmaceutical Preparation}

Synthesis of the labeling precursor, kit preparation, and subsequent ${ }^{99} \mathrm{~m}$ Tc-labeling were performed as previously described $(21,22)$. Briefly, the kit for preparation of ${ }^{99 \mathrm{~m} T c-3 P R G D 2}$ was formulated by combining $20 \mu \mathrm{g}$ of hydrazinonicotinamide-3PRGD2, $5 \mathrm{mg}$ of trisodium triphenylphosphine-3,3',3' ${ }^{\prime \prime}$-trisulfonate (TPPTS), $6.5 \mathrm{mg}$ of tricine, $40 \mathrm{mg}$ of mannitol, $38.5 \mathrm{mg}$ of disodium succinate hexahydrate, and $12.7 \mathrm{mg}$ of succinic acid. For ${ }^{99 \mathrm{~m}} \mathrm{Tc}$ radiolabeling, to the kit vial was added $1 \mathrm{~mL}$ of $1,110-1,850 \mathrm{MBq}(30-50 \mathrm{mCi})$ of ${ }^{99} \mathrm{mcO}_{4}{ }^{-}$saline solution, and then the vial was water-bathed at $100^{\circ} \mathrm{C}$ for $15-20 \mathrm{~min}$. The resulting solution was analyzed by instant thin-layer chromatography using Gelman Sciences silica-gel paper strips and a 1:1 mixture of acetone and saline as eluant. For clinical use, the radiochemical purity was always greater than $95 \%$. The reaction mixture was then diluted to approximately $370 \mathrm{MBq} / \mathrm{mL}$ $(10 \mathrm{mCi} / \mathrm{mL})$ with saline and was filtered with a $0.20-\mu \mathrm{m}$ MillexLG filter (EMD Millipore). Each patient was injected with 11.1 $\mathrm{MBq}(0.3 \mathrm{mCi})$ of ${ }^{99 \mathrm{~m} T c-3 P R G D 2}$ per kilogram.

\section{Imaging Protocol}

The SPECT scanner of each center is listed in Table 1. All the scanners were dual-head $\gamma$-cameras, using low-energy high-resolution collimators and a $20 \%$ energy window centered on $140 \mathrm{keV}$. After intravenous injection of ${ }^{99 \mathrm{~m} T c-3 P R G D 2}$, anterior and posterior planar scans of the whole body and SPECT scans of the chest were obtained at dual time points of 1 and $4 \mathrm{~h}$, with a \pm 20 -min time window to complete the imaging procedure. The speed of whole-body scanning was set at $10 \mathrm{~cm} / \mathrm{min}$, followed by SPECT of the chest (zoom, $\times 1,30 \mathrm{~s} /$ frame $/ 6^{\circ}$ ) with the patients' arms raised

TABLE 1

SPECT Systems and Recruited Patient Number of 6 Participant Centers

\begin{tabular}{llc}
\hline \multicolumn{1}{c}{ Centers } & \multicolumn{1}{c}{ SPECT system } & Recruited patients \\
\hline $\begin{array}{l}\text { The First Affiliated Hospital of Fujian Medical } \\
\text { University, Fuzhou }\end{array}$ & Infinia Hawkeye, GE Healthcare & 19 \\
$\begin{array}{l}\text { Peking Union Medical College Hospital, } \\
\text { Beijing (the organizer center) }\end{array}$ & Precedence 16, Philips Healthcare & 17 \\
$\begin{array}{l}\text { Southwest Hospital of the Third Military } \\
\text { Medical University, Chongqing }\end{array}$ & Millennium MPR, GE Healthcare & 12 \\
$\begin{array}{l}\text { Beijing Tongren Hospital, Beijing } \\
\text { China-Japan Union Hospital, Changchun }\end{array}$ & Infinia Hawkeye4, GE Healthcare & 11 \\
$\begin{array}{l}\text { The First Affiliated Hospital of Xi'an } \\
\text { Jiaotong University, Xi'an }\end{array}$ & Skylight, Philips Healthcare & 9 \\
\hline
\end{tabular}


TABLE 2

Basic Information on Patients

\begin{tabular}{|c|c|c|c|c|}
\hline \multirow[b]{2}{*}{ Diagnosis } & \multirow[b]{2}{*}{ Number } & \multicolumn{2}{|r|}{ Sex } & \multirow[b]{2}{*}{ Age (y) } \\
\hline & & Male & Female & \\
\hline Malignant & 58 & 44 & 14 & $63 \pm 9$ \\
\hline Adenocarcinoma & 23 & 15 & 8 & $64 \pm 10$ \\
\hline $\begin{array}{l}\text { Squamous cell } \\
\text { carcinoma }\end{array}$ & 24 & 22 & 2 & $63 \pm 10$ \\
\hline Small cell lung cancer & 2 & 1 & 1 & 53,61 \\
\hline $\begin{array}{l}\text { Adenocarcinoma plus } \\
\text { small cell lung cancer }\end{array}$ & 1 & 1 & 0 & 66 \\
\hline $\begin{array}{l}\text { Bronchioloalveolar } \\
\text { carcinoma }\end{array}$ & 1 & 0 & 1 & 58 \\
\hline Sarcoma & 1 & 1 & 0 & 68 \\
\hline Melanoma & 1 & 1 & 0 & 57 \\
\hline $\begin{array}{l}\text { Lung malignancy, } \\
\text { type undefined }\end{array}$ & 5 & 3 & 2 & $65 \pm 8$ \\
\hline Benign & 12 & 5 & 7 & $62 \pm 11$ \\
\hline Chronic inflammation & 6 & 3 & 3 & $61 \pm 9$ \\
\hline $\begin{array}{l}\text { Granuloma of } \\
\text { tuberculosis }\end{array}$ & 1 & 0 & 1 & 53 \\
\hline Fungal infection & 1 & 1 & 0 & 70 \\
\hline Adenoma & 1 & 0 & 1 & 69 \\
\hline Sclerosing hemangioma & 1 & 1 & 0 & 78 \\
\hline Mature cystic teratoma & 1 & 0 & 1 & 43 \\
\hline $\begin{array}{l}\text { Arteriovenous } \\
\text { malformation with } \\
\text { inflammation }\end{array}$ & 1 & 0 & 1 & 70 \\
\hline Total & 70 & 49 & 21 & $63 \pm 9$ \\
\hline
\end{tabular}

above the head. The images were acquired using the optimized parameters of each SPECT system. The Digital Imaging and Communications in Medicine image files of each patient were saved in optic disks and transferred to a Xeleris 3.0 workstation (GE Healthcare) for centralized reconstruction, reading, and analysis.

\section{Image Analysis}

Image analysis was completed by 6 experienced nuclear medicine physicians through consensus reading masked to the source, history, and pathologic diagnosis of the patients. The CT images were provided for reference. In visual analysis, the image quality, number of lesions, and diagnosis (benign or malignant) were documented. The number of lesions included only focal uptake lesions and excluded uncertain uptake and heterogeneous distribution. The readers were allowed to make their diagnosis according to their experience with volume effect and necrosis of the lesions and considering the possible metastatic lesions in the body. For semiquantitative analysis, tumor-to-background (T/B) and tumor-to-mediastinum (T/M) ratios of whole-body planar images and SPECT images at dual time points were measured and calculated by the same person using a consistent standard. Briefly, for the analysis of whole-body planar images, a circular or ovoid region of interest (ROI) was set over the tumor on the planar images; the tumor ROI was drawn by a preset threshold of $42 \%$ and was adjusted minimally according to visual assessment. Then a mirror ROI was set over the contralateral normal lung as a control. The T/B ratios were calculated by (mean counts of the tumor ROI)/(mean counts of the control ROI). The T/M ratios were calculated similarly, but the control ROI was placed over the mediastinum. In the analysis of SPECT images, a volume-ofinterest (VOI) method was used to obtain both maximum and mean counts of the tumor and to make the measurement more reproducible, the T/B and T/M ratios were calculated by dividing the maximum value of the tumor VOI by the mean value of the control VOI. For cases in which more than 1 lesion was detected in the lung, the highest-uptake lesion was used for analysis.

In the semiquantitative method, a positive threshold was determined using the area under receiver-operating-characteristic curve, whereas in the visual analysis, a lung lesion with ${ }^{99 m}$ Tc-3PRGD2 uptake higher than soft tissue was considered positive. The readers were allowed to make a decision considering the volume effect and necrosis of the lesions, including the metastases.

\section{Statistical Analysis}

A self-paired $t$ test was used to compare the T/B and T/M ratios obtained from the same patients. The planar and SPECT images at dual time points of 1 and $4 \mathrm{~h}$ were compared. The difference between malignant and benign lesions was analyzed using the Student $t$ test. The T/B and T/M ratios were expressed as mean $\pm \mathrm{SD}$, with a $P$ value less than 0.05 considered significant. In addition, the visual and semiquantitative diagnoses were made separately and were compared with the standard of truth. The sensitivity, specificity, accuracy, positive predictive value, and negative predictive value were used to determine the efficacy of ${ }^{99 m} \mathrm{Tc}-3 \mathrm{PRGD} 2$ for the diagnosis of lung cancer.

\section{RESULTS}

\section{Distribution of ${ }^{99 m T c-3 P R G D 2 ~ i n ~ H u m a n ~ B o d y ~}$}

The image quality of ${ }^{99 m} \mathrm{Tc}-3 \mathrm{PRGD} 2$ scans was good for the 70 enrolled patients. The distribution of ${ }^{99 \mathrm{~m}} \mathrm{Tc}-3$ PRGD2 in the human body could be clearly observed through the anterior and posterior whole-body images (Fig. 1). Except for the intense accumulation in the kidneys and bladder corresponding to the main excretion pathway, there was moderate ${ }^{99 \mathrm{~m} T c-3 P R G D 2}$ uptake in the liver, spleen, intestines, nasopharyngeal region, and bone marrow. The low background in the lungs and mediastinum allowed for easy discrimination of thoracic lesions; however, abdominal lesions were relatively harder to identify. Compared with the images obtained at $1 \mathrm{~h}$, the 4-h images showed lower background in the blood and muscles but with much more prominent uptake in the intestines and bone marrow (Fig. 1).

\section{Efficacy of ${ }^{99 m}$ Tc-3PRGD2 Imaging for Evaluation of Lung Tumor}

With low background in the lungs and mediastinum, most malignant lung tumors, metastases, and some benign lesions were clearly observed on the ${ }^{99 \mathrm{~m} T c-3 P R G D 2}$ images (Figs. 1 and 2). If a tumor with a T/B ratio greater than 1.2 on the 1-h planar images or a T/B greater than 1.5 on the 1-h SPECT images was considered positive, the sensitivity was $88 \%$ for both criteria and reached $93 \%-$ $97 \%$ in the visual analysis when volume effect, necrosis, and metastasis were also considered (Table 3). The smallest positive lesion in this group of patients was $1.9 \times 2.0 \times 2.0$ $\mathrm{cm}$ measured on the CT images, with a T/B ratio of 1.4 and 2.2 on the planar and SPECT images, respectively.

For the 58 patients with proven lung malignancies, the mean T/B ratios of the lung tumors were $1.65 \pm 0.47$ for 


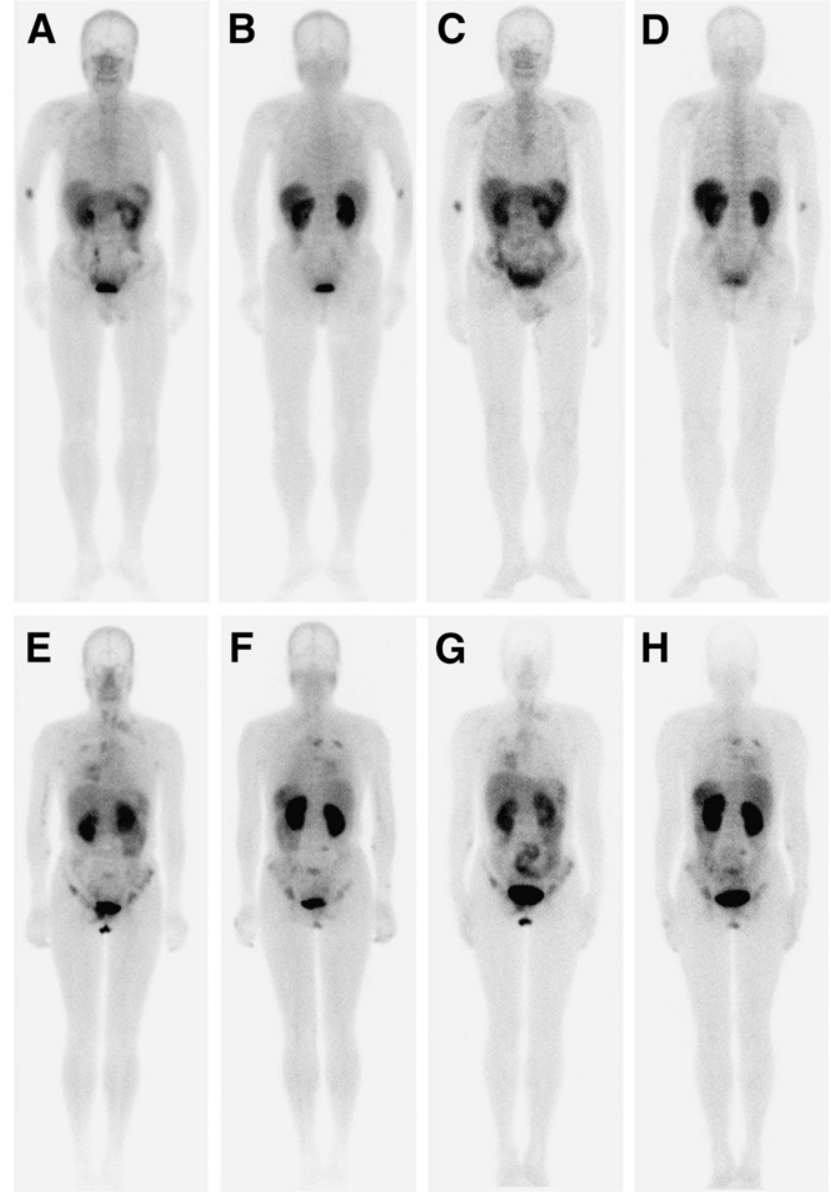

FIGURE 1. Negative and positive whole-body scans of $99 \mathrm{mTC}$ 3PRGD2. (A-D) Anterior and posterior whole-body images at $1 \mathrm{~h}$ ( $A$ and $B$ ) and $4 \mathrm{~h}$ ( $C$ and $D$ ) of 75-y-old man with low 99mTc-3PRGD2 uptake in chronic inflammation lesion at right upper lung (T/B, 1.1) and enlarged lymph nodes in mediastinum. $(E-H)$ Anterior and posterior whole-body images at $1 \mathrm{~h}(\mathrm{E}$ and $\mathrm{F})$ and $4 \mathrm{~h}(\mathrm{G}$ and $\mathrm{H})$ of $57-\mathrm{y}-$ old woman with lung adenocarcinoma at right middle lobe $(T / B, 2.4)$, accompanied by mediastinal and left supraclavicular lymph node involvement and extensive bone metastases.

planar scanning and $2.78 \pm 1.52$ for SPECT at $1 \mathrm{~h}$ after intravenous injection of ${ }^{99 \mathrm{~m} T c-3 P R G D 2}$ - ratios significantly higher than those of the benign lesions (T/B ratio, $1.25 \pm 0.35$ for planar imaging, $P<0.01$, and $1.86 \pm 1.06$ for SPECT, $P$ $<0.05$ ) (Fig. 3). However, the specificities of 58\%-67\% were relatively low in this group of patients (Table 3 ).

The efficacy of ${ }^{99 m} \mathrm{Tc}-3 \mathrm{PRGD} 2$ imaging for the assessment of lung lesions was also compared between the planar and SPECT images, 1- and 4-h acquisitions, visual and semiquantitative analyses, and $\mathrm{T} / \mathrm{B}$ and $\mathrm{T} / \mathrm{M}$ ratios.

Comparison Between Whole-Body Planar Scanning and SPECT. The lung lesions on the SPECT images had significantly higher $\mathrm{T} / \mathrm{B}$ and $\mathrm{T} / \mathrm{M}$ ratios than the same lesions on the planar images obtained at either 1 or $4 \mathrm{~h}$ for both malignant and benign lesions (Fig. 3, $P<0.001$ ). The efficacy of planar imaging and SPECT was comparable for the detection of the primary tumor (Table 3 ).
More lesions were detected on the chest SPECT images than on the planar images within the same region: 120 and 124 lesions were found on the chest SPECT images obtained at 1 and $4 \mathrm{~h}$, respectively, whereas only 117 and 118 lesions were detected on the corresponding planar scans, respectively. However, the whole-body planar scan also held advantages because it showed lesions out of the field of view of the chest SPECT scan.

Comparison Between 1- and 4-H Images. As shown in Figure 3, for both benign and malignant lesions on either planar or SPECT images, the mean ratios of T/B and T/M showed an increase at $4 \mathrm{~h}$ as compared with 1 -h ratios. In visual analysis, the background in the lungs and soft tissues appeared lower at $4 \mathrm{~h}$ (Fig. 1), with the sensitivity increased from $93 \%-97 \%$ to $98 \%$ and the specificity from $58 \%$ to $67 \%$. However, in semiquantitative analysis, the sensitivity of the 4-h imaging decreased from $88 \%$ to $72 \%$, with a comparable specificity of 58\%-67\% (Table 3). Moreover, the image quality at $4 \mathrm{~h}$ was affected by lower counts and higher bowel and bone marrow uptake (Fig. 1).

Comparison Between Visual and Semiquantitative Analyses. The sensitivity of the visual analysis (93\%-98\%) was remarkably higher than that of the semiquantitative analysis (77\%-88\%) when the volume effect, tumor necrosis, and metastasis were allowed to be considered in the analysis (Table 3). However, the specificity was comparable, ranging from $58 \%$ to $67 \%$.

Comparison Between $T / B$ and $T / M$ Ratios in Semiquantitative Evaluation. The T/B ratios of the lesions were significantly higher than the T/M ratios on all the wholebody and SPECT images obtained at 1 and $4 \mathrm{~h}(P<0.001)$. It seemed that the $\mathrm{T} / \mathrm{M}$ ratios had an efficiency similar to the T/B ratios at differentiating malignant tumors from benign lesions, but these ratios did not contribute more to the diagnosis and evaluation of lung lesions (Fig. 3). Therefore, the final analysis used T/B ratio only.

\section{9mTC-3PRGD2 Imaging for Assessment of Metastasis}

In a lesion-based analysis of the 58 patients diagnosed with malignancy, 108 of the 196 (55\%) possible metastases based on a comprehensive imaging work-up were observed on the 1-h whole-body planar images (mainly lymph node involvement and bone lesions). When imaged at $4 \mathrm{~h}, 117$ lesions $(60 \%)$ could be seen, in particular more lymph nodes as the background decreased.

In an analysis of only bone metastasis in 21 patients who underwent bone scanning, 89 suspected lesions were found on the ${ }^{99 \mathrm{~m}} \mathrm{Tc}-\mathrm{MDP}$ whole-body scans of bone, and 63 lesions (71\%) were detected on the $99 \mathrm{~m}$ Tc-3PRGD2 whole-body images at $1 \mathrm{~h}$, but the number of detectable lesions decreased to $50(56 \%)$ at $4 \mathrm{~h}$ because of higher bone marrow uptake in the delayed imaging.

\section{DISCUSSION}

${ }^{99 m}$ Tc-3PRGD2, a novel RGD-based radiotracer targeting the integrin $\alpha_{V} \beta_{3}$ receptor, has recently been trans- 
FIGURE 2. True- and false-positive ${ }^{99 \mathrm{mTC}}$ 3PRGD2 SPECT/CT scans. (A-C) CT (A), SPECT (B), and fusion (C) images of $71-y-$ old woman with moderate differentiated squamous cell carcinoma showing intense 99mTc-3PRGD2 accumulation near hilus of left upper lung (arrow), accompanied by distal obstructive atelectasis with mild uptake (cross). (D-F) CT (D), 99mTc-3PRGD2 SPECT (E), and ${ }^{18} \mathrm{~F}-\mathrm{FDG}$ PET (F) images of 53 -y-old man with tuberculosis granuloma at right upper lung. ${ }^{99 m T c-3 P R G D 2 ~ S P E C T ~ i m a g e ~}$ showed moderate uneven uptake at lesion, with possible central necrosis (cross) and mild to moderate uptake in bone marrow, whereas ${ }^{18} \mathrm{~F}-\mathrm{FDG}$ PET image showed intense uptake of lesion.
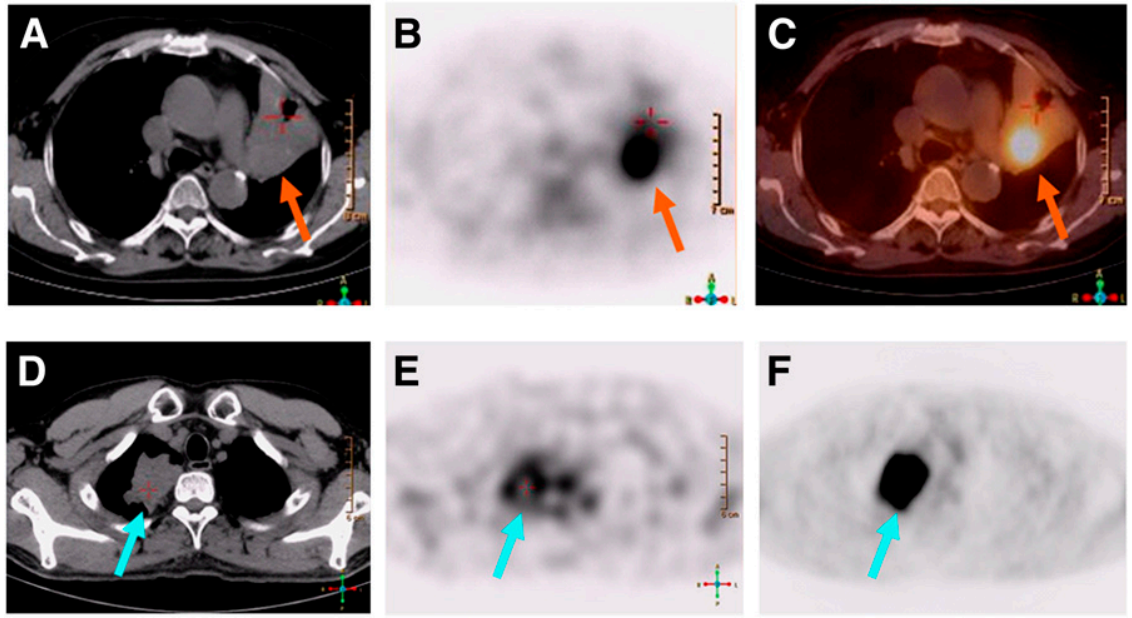

lated into clinical trials after the preliminary clinical applications of several other RGD-based tracers, such as ${ }^{18} \mathrm{~F}$-galacto-RGD, ${ }^{18} \mathrm{~F}-\mathrm{AH} 111585$, and ${ }^{99 \mathrm{~m}} \mathrm{Tc}-\mathrm{NC} 100692$ $(11-14,16,17,22)$. Compared with the ${ }^{18} \mathrm{~F}$-labeled tracers for PET, ${ }^{99 \mathrm{~m}}$ Tc-3PRGD2 is a SPECT tracer that holds the advantage of being more broadly available. Moreover, the preparation procedure for ${ }^{99 \mathrm{~m}} \mathrm{Tc}-3 \mathrm{PRGD} 2$ is simple, efficient, and reproducible, allowing a kit formulation and the easy availability for routine clinical use $(21,22)$. ${ }^{99 m} \mathrm{Tc}-$ 3PRGD2 was designed as a dimeric cyclic RGD peptide that inserted 2 PEG4 between the 2 RGD motifs instead of just a cyclic RGD monomer of NC100692 (16,17). The tracer was expected to have significantly increased binding affinity to the integrin $\alpha_{V} \beta_{3}$ receptor and thus would potentially result in a higher tumor uptake in vivo (23-26); the higher uptake has been proved in mouse models, nonhuman primates, and patients (18-22). Therefore, ${ }^{99 m}$ Tc-3PRGD2 possessed great potential for detecting integrin $\alpha_{v} \beta_{3}-$ positive tumors in clinical settings. This study provided the preliminary results of the first multicenter study designed to evaluate the efficacy of ${ }^{99 \mathrm{~m}} \mathrm{Tc}-3 \mathrm{PRGD} 2$ for the diagnosis and evaluation of lung cancer.

Seventy patients with suspected lung lesions were involved in the study, and 58 patients were finally proven to have malignancies. ${ }^{99 m}$ Tc-3PRGD2 imaging showed good efficacy for the detection of the lung tumors. At $1 \mathrm{~h}$ after intravenous injection of ${ }^{99 \mathrm{~m}} \mathrm{Tc}-3 \mathrm{PRGD} 2$, the mean T/B ratios of 1.65 for planar imaging and 2.78 for SPECT were relatively high. The sensitivity was $88 \%$ in semiquantitative analysis and reached $93 \%-97 \%$ in visual analysis if the volume effect, necrosis, and metastasis were also considered (Table 2). However, the specificity of 58\%-67\% in this group of patients was relatively low, even if the benign lesions showed significantly lower uptake. This lower uptake might have been caused by three factors: the first was the selection bias of benign conditions. All of the lung lesions of benign cases were highly suspected of malignancy, and surgical removal or biopsy was suggested and performed. Second, the high expression of integrin $\alpha_{V} \beta_{3}$ receptor was found not only in tumor angiogenesis and various tumor cells but also in inflammatory angiogenesis and other related processes $(27,28)$. Third, there were only 12 benign cases in this group. The patient number was too small to obtain a result with confidence. Interestingly, in a case of tuberculosis granuloma, the lesion had much lower uptake of ${ }^{99 \mathrm{~m}} \mathrm{Tc}-3 \mathrm{PRGD} 2$ than of ${ }^{18} \mathrm{~F}-\mathrm{FDG}$, and 99mTc-3PRGD2 SPECT showed more details of the lesion, including the central necrosis (Fig. 2).

TABLE 3

Efficacy of 99mTc-3PRGD2 Imaging for Diagnosis of Primary Lung Cancer

\begin{tabular}{|c|c|c|c|c|c|c|c|c|}
\hline Analysis & $\begin{array}{l}\text { Time } \\
\text { (h) }\end{array}$ & Mode & $\begin{array}{l}\text { Criteria for } \\
\text { positivity }\end{array}$ & $\begin{array}{c}\text { Sensitivity } \\
(\%)\end{array}$ & $\begin{array}{c}\text { Specificity } \\
(\%)\end{array}$ & $\begin{array}{c}\text { Accuracy } \\
(\%)\end{array}$ & $\begin{array}{c}\text { Positive predictive } \\
\text { value }(\%)\end{array}$ & $\begin{array}{c}\text { Negative predictive } \\
\text { value }(\%)\end{array}$ \\
\hline \multirow[t]{4}{*}{ Semiquantitative } & 1 & Planar & $\mathrm{T} / \mathrm{B}>1.2$ & 88 & 67 & 84 & 93 & 53 \\
\hline & & SPECT & $\mathrm{T} / \mathrm{B}>1.5$ & 88 & 58 & 83 & 91 & 50 \\
\hline & 4 & Planar & $\mathrm{T} / \mathrm{B}>1.4$ & 72 & 60 & 70 & 91 & 26 \\
\hline & & SPECT & $\mathrm{T} / \mathrm{B}>1.9$ & 72 & 62 & 70 & 89 & 33 \\
\hline \multirow[t]{4}{*}{ Visual } & 1 & Planar & * & 93 & 58 & 87 & 92 & 64 \\
\hline & & SPECT & * & 97 & 58 & 90 & 92 & 78 \\
\hline & 4 & Planar & * & 98 & 67 & 93 & 93 & 89 \\
\hline & & SPECT & * & 98 & 67 & 93 & 93 & 89 \\
\hline
\end{tabular}

*Higher than soft tissue, but also considered volume effect, necrosis, and metastasis.

Data are for analysis of lung lesions in 70 patients (malignant, 58; benign, 12). 


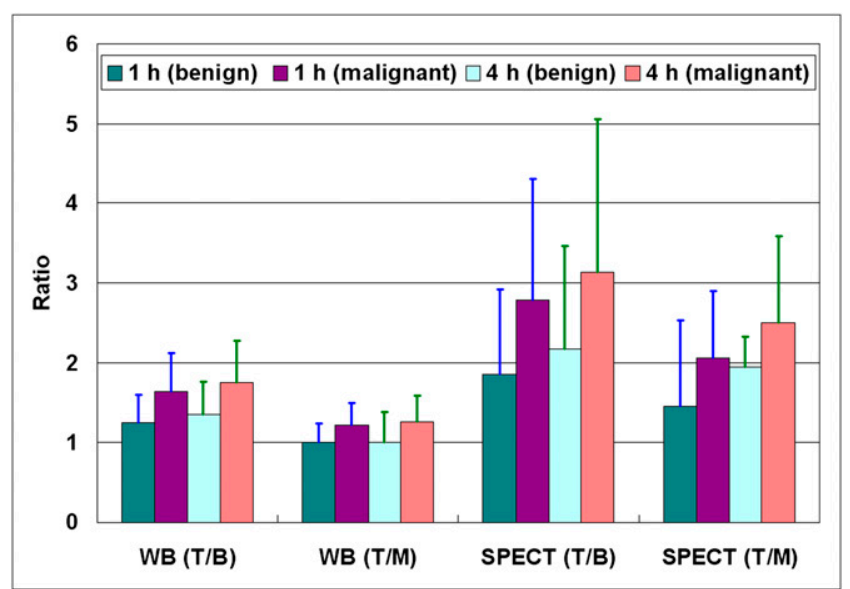

FIGURE 3. Comparison of $T / B$ and $T / M$ ratios (mean $\pm S D$ ) of benign and malignant lesions between whole-body (WB) planar and SPECT images obtained at 1 and $4 \mathrm{~h}$, respectively.

For the assessment of metastases, the biodistribution of ${ }^{99 \mathrm{~m}} \mathrm{Tc}-3 \mathrm{PRGD} 2$ in the body was the most important factor influencing the detection efficiency of different regions. The low ${ }^{99 m}$ Tc-3PRGD2 uptake in the thoracic region gave high sensitivity for the detection of primary lung cancer. The low uptake also seemed useful to evaluate hilar, mediastinal, and supraclavicular lymph node involvement. This new imaging agent could be sensitive to evaluating breast cancer, as reported using the other RGD tracers $(14,16)$. 99mTc-3PRGD2 also had low background in the normal brain, and thus it could also be possibly used for imaging of brain metastasis from lung cancer, though there were no such cases involved in this study. Bone marrow showed mild to moderate ${ }^{99 m}$ Tc-3PRGD2 uptake at $1 \mathrm{~h}$ after intravenous injection-this uptake was much more prominent in the delayed imaging at $4 \mathrm{~h}$. Therefore, only $71 \%$ of the suspected bone metastases on the ${ }^{99 \mathrm{~m}} \mathrm{Tc}-\mathrm{MDP}$ bone scan were observed by ${ }^{99 \mathrm{~m} T c-3 P R G D 2}$ imaging at $1 \mathrm{~h}$, with the percentage decreased to $56 \%$ at $4 \mathrm{~h}$. Most of the organs with moderate to intense ${ }^{99 \mathrm{~m}} \mathrm{Tc}-3 \mathrm{PRGD} 2$ accumulation, such as the kidneys, bladder, spleen, liver, and intestines, were located in the abdomen and pelvis, making the assessment of metastases relatively challenging in this region. However, SPECT/CT of the abdomen, which was performed in only a few cases of this group (data not shown), indicated that it was still useful to evaluate the ${ }^{99 \mathrm{~m}} \mathrm{Tc}-$ 3PRGD2 uptake in a known lesion, especially when reading with coregistered CT images. Moreover, the fact that the bowel uptake was relatively low at $1 \mathrm{~h}$ and might change over time could be useful for differentiation of tumor from physiologic accumulation.

As to the technical aspects of imaging and analysis, we contrasted the different methods for their strengths and weaknesses. Whole-body planar scans provided a panoramic image from head to toe, with acceptable sensitivity within $20 \mathrm{~min}$, but they were limited in delineating the exact location of the tumors. By contrast, SPECT showed significantly higher $\mathrm{T} / \mathrm{B}$ ratios and could achieve precise positioning, especially when CT images could be used for reference. However, there was a need to coordinate the balance between the image quality and the acquisition time. The axial field of view was also limited for SPECT. In general, the 1-h whole-body planar and SPECT images were enough for evaluation of lung lesions. The thoracic background was lower, and the T/B ratios were moderately increased in the delayed imaging at $4 \mathrm{~h}$, showing more lymph node metastases. However, bone metastases were less observable at $4 \mathrm{~h}$ because of the higher bone marrow uptake. The lower counts and higher bowel uptake also weakened the image quality. Moreover, the requirement for another imaging procedure at $4 \mathrm{~h}$ was both time-consuming and inconvenient for patients. Visual and semiquantitative analyses often play a complementary role. The visual analysis considering the volume effect, necrosis, and metastases improved the sensitivity. Although the 2 semiquantitative ratios, T/B and T/M, showed similar efficiency for the differentiation of lung tumors, the T/B ratio showed significantly higher value and might be more suitable for evaluation. However, the T/M ratio might also have its application in conditions such as those with diffuse lung involvement.

There are also some limitations in this study. First, as a multicenter clinical study, the data obtained from different centers using different SPECT systems may have some bias. Several means were adopted to minimize the influence: the same standardized operating procedure was used in the 6 centers; all the image data were transferred to the same workstation for centralized reconstruction, reading, and analysis; the images were read in consensus by 6 experienced nuclear medicine physicians masked to the source, history, and pathologic diagnosis of the patients; and the T/B and T/M ratios were measured by the same person using a consistent standard. Second, the number of enrolled patients, especially those with benign lesions, was still inadequate. This study shows only the preliminary result of the multicenter study, and follow-up studies with more patients would probably resolve these problems. Further studies are also needed to investigate the correlation between ${ }^{99 \mathrm{~m}} \mathrm{Tc}-3 \mathrm{PRGD} 2$ uptake and integrin $\alpha_{V} \beta_{3}$ expression and to compare the uptake of ${ }^{99 \mathrm{~m} T c-3 P R G D 2}$ and ${ }^{18} \mathrm{~F}-\mathrm{FDG}$ in both tumors and benign lesions. The importance of the present data is that noninvasive molecular characterization of $\alpha_{v} \beta_{3}$ integrin expression in lung cancer is clinically feasible using the new SPECT tracer and may have more important implications in the further development of therapeutics.

\section{CONCLUSION}

The preliminary results of this multicenter study indicate

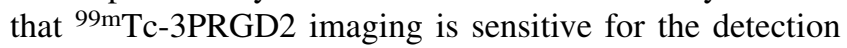
of lung malignancies, although the specificity is relatively low. Whole-body planar scanning and chest SPECT are complementary for the evaluation of the primary tumor and metastasis. The 1-h imaging is good enough for diagnosis, and the visual analysis may aid the semiquantitative assessment. These results merit further investigation of the 


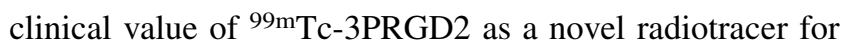
integrin $\alpha_{V} \beta_{3}$ receptor imaging.

\section{DISCLOSURE STATEMENT}

The costs of publication of this article were defrayed in part by the payment of page charges. Therefore, and solely to indicate this fact, this article is hereby marked "advertisement" in accordance with 18 USC section 1734.

\section{ACKNOWLEDGMENTS}

This work was financially supported, in part, by the Capital Special Project for Featured Clinical Application in 2011 (Z111107058811096), the National Natural Science Foundation of China (NSFC) projects $(30870725,30870728$, 30930030, 30900373, 81000625, 81071189, and 81171369), the Outstanding Youth Fund (81125011), a “973" project (2011CB707703), and grants from the Ministry of Science and Technology of China (2011YQ030114 and 2012ZX09102301-018). No other potential conflict of interest relevant to this article was reported.

\section{REFERENCES}

1. Hynes RO. Integrins: a family of cell surface receptors. Cell. 1987;48:549-554.

2. Horton MA. The $\alpha_{V} \beta_{3}$ integrin "vitronectin receptor." Int J Biochem Cell Biol. 1997;29:721-725.

3. Plow EF, Haas TA, Zhang L, Loftus J, Smith JW. Ligand binding to integrins. J Biol Chem. 2000;275:21785-21788.

4. Eliceiri BP, Cheresh DA. The role of alpha $\mathrm{v}$ integrins during angiogenesis: insights into potential mechanisms of action and clinical development. J Clin Invest. 1999;103:1227-1230.

5. Brooks PC, Montgomery AM, Rosenfeld M, et al. Integrin $\alpha_{\mathrm{V}} \beta_{3}$ antagonists promote tumor regression by inducing apoptosis of angiogenic blood vessels. Cell. 1994;79:1157-1164.

6. Ruoslahti E, Pierschbacher MD. New perspectives in cell adhesion: RGD and integrins. Science. 1987;238:491-497.

7. Haubner R, Wester HJ, Reuning U, et al. Radiolabeled $\alpha_{\mathrm{V}} \beta_{3}$ integrin antagonists: a new class of tracers for tumor targeting. J Nucl Med. 1999;40:1061-1071.

8. Haubner R, Wester HJ, Weber WA, Schwaiger M. Radiotracer based strategies to image angiogenesis. Q J Nucl Med. 2003;47:189-199.

9. Haubner R, Weber WA, Beer AJ, et al. Noninvasive visualization of the activated $\alpha_{\mathrm{V}} \beta_{3}$ integrin in cancer patients by positron emission tomography and $\left[{ }^{18} \mathrm{~F}\right]$ galacto-RGD. PLoS Med. 2005;2:e70.

10. Haubner R, Wester HJ, Weber WA, et al. Noninvasive imaging of $\alpha_{\mathrm{V}} \beta_{3}$ integrin expression using ${ }^{18} \mathrm{~F}$-labeled RGD-containing glycopeptide and positron emission tomography. Cancer Res. 2001;61:1781-1785.
11. Beer AJ, Haubner R, Goebel M, et al. Biodistribution and pharmacokinetics of the $\alpha_{\mathrm{V}} \beta_{3}$-selective tracer ${ }^{18} \mathrm{~F}$-galacto-RGD in cancer patients. J Nucl Med. 2005;46:1333-1341.

12. Beer AJ, Haubner R, Sarbia M, et al. Positron emission tomography using $\left[{ }^{18} \mathrm{~F}\right]$ galacto-RGD identifies the level of integrin $\alpha_{\mathrm{V}} \beta_{3}$ expression in man. Clin Cancer Res. 2006;12:3942-3949.

13. McParland BJ, Miller MP, Spinks TJ, et al. The biodistribution and radiation dosimetry of the Arg-Gly-Asp peptide ${ }^{18} \mathrm{~F}$-AH111585 in healthy volunteers. J Nucl Med. 2008;49:1664-1667.

14. Kenny LM, Coombes RC, Oulie I, et al. Phase I trial of the positron-emitting Arg-Gly-Asp peptide radioligand ${ }^{18} \mathrm{~F}-\mathrm{AH} 111585$ in breast cancer patients. J Nucl Med. 2008;49:879-886.

15. Indrevoll B, Kindberg GM, Solbakken M, et al. NC-100717: a versatile RGD peptide scaffold for angiogenesis imaging. Bioorg Med Chem Lett. 2006;16: 6190-6193.

16. Bach-Gansmo T, Danieleeon R, Saracco A, et al. Integrin receptor imaging of breast cancer: a proof-of-concept study to evaluate ${ }^{99 \mathrm{~m}} \mathrm{Tc}-\mathrm{NC} 100692 . \mathrm{J} \mathrm{Nucl}$ Med. 2006;47:1434-1439.

17. Axelsson R, Bach-Gansmo T, Castell-Conesa J, McParland BJ. Study Group. An open-label, multi-center, phase 2 a study to assess the feasibility of imaging metastases in late-stage cancer patients with the $\alpha_{\mathrm{V}} \beta_{3}$-selective angiogenesis

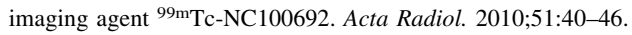

18. Shi J, Wang L, Kim YS, et al. Improving tumor uptake and excretion kinetics of ${ }^{99 \mathrm{~m}} \mathrm{Tc}$-labeled cyclic arginine-glycine-aspartic (RGD) dimmers with triglycine linkers. J Med Chem. 2008;51:7980-7990.

19. Liu Z, Jia B, Shi J, et al. Tumor uptake of the RGD dimeric probe ${ }^{99 m} \mathrm{Tc}-\mathrm{G}_{3}-2 \mathrm{P}_{4^{-}}$ $\mathrm{RGD}_{2}$ is correlated with integrin $\alpha_{\mathrm{V}} \beta_{3}$ expressed on both tumor cells and neovasculature. Bioconjug Chem. 2010;21:548-555

20. Zhou Y, Kim YS, Chakraborty S, Shi J, Gao H, Liu S. ${ }^{99 m}$ Tc-labeled cyclic RGD peptides for noninvasive monitoring of tumor integrin $\alpha_{\mathrm{V}} \beta_{3}$ expression. Mol Imaging. 2011;10:386-397.

21. Jia B, Liu Z, Zhu Z, et al. Blood clearance kinetics, biodistribution, and radiation dosimetry of a kit-formulated integrin $\alpha_{\mathrm{V}} \beta_{3}$-selective radiotracer ${ }^{99 \mathrm{~m}}$ Tc-3PRGD2 in non-human primates. Mol Imaging Biol. 2011;13:730-736.

22. Ma Q, Ji B, Jia B, et al. Differential diagnosis of solitary pulmonary nodules using ${ }^{99 m}$ Tc-3P $4-\mathrm{RGD}_{2}$ scintigraphy. Eur J Nucl Med Mol Imaging. 2011;38: 2145-2152.

23. Janssen M, Oyen W, Massuger LF, et al. Comparison of a monomeric and dimeric radiolabeled RGD-peptide for tumor imaging. Cancer Biother Radiopharm. 2002;17:641-646.

24. Dijkgraaf I, Kruijtzer JA, Liu S, et al. Improved targeting of the $\alpha_{V} \beta_{3}$ integrin by multimerisation of RGD peptides. Eur J Nucl Med Mol Imaging. 2007;34:267-273.

25. Thumshirn G, Hersel U, Goodman SL, et al. Multimeric cyclic RGD peptides as potential tools for tumor targeting: solid-phase peptide synthesis and chemoselective oxime ligation. Chemistry. 2003;9:2717-2725.

26. Chen X, Park R, Shahinian AH, et al. Pharmacokinetics and tumor retention of ${ }^{125} \mathrm{I}-$ labeled RGD peptide are improved by PEGylation. Nucl Med Biol. 2004;31:11-19.

27. Pichler BJ, Kneilling M, Haubner R, et al. Imaging of delayed-type hypersensitivity reaction by PET and ${ }^{18} \mathrm{~F}$-galacto-RGD. J Nucl Med. 2005;46:184-189.

28. McDonald DM, Choyke PL. Imaging of angiogenesis: From microscope to clinic. Nat Med. 2003;9:713-725. 